\title{
Lamination Curing Method for Inkjet Printed Flexible Angle Sensors
}

This paper was downloaded from TechRxiv (https://www.techrxiv.org).

LICENSE

CC BY-NC-SA 4.0

SUBMISSION DATE / POSTED DATE

08-10-2021 / 15-10-2021

CITATION

Türkmen, Dila; Acer Kalafat, Merve (2021): Lamination Curing Method for Inkjet Printed Flexible Angle Sensors. TechRxiv. Preprint. https://doi.org/10.36227/techrxiv.16776145.v1

$\mathrm{DOI}$

10.36227/techrxiv.16776145.v1 


\title{
Lamination Curing Method for Inkjet Printed Flexible Angle Sensors
}

\author{
Dila Türkmen, Merve Acer Kalafat
}

\begin{abstract}
This work has been submitted to the IEEE for possible publication. Copyright may be transferred without notice, after which this version may no longer be accessible.

Abstract-In this paper we present the lamination curing as a stand-alone method to activate the silver nanoparticle (Ag NP) inkjet printed angle sensors on a $0.14 \mathrm{~mm}$ PET substrate, with a desktop printer. (With the term "lamination curing", we refer passing the printed sample through a lamination machine, without any actual laminating purpose, only for curing.) We compared the method with the oven curing, which is the widest used method for the intended sensors, and found that lamination cured sensors give lower sheet resistance, lower fabrication uncertainty and more consistent angle sensing behaviors with higher sensing performance. Different curing parameters are inspected and a process under 3 minutes is achieved giving a $0.06 \Omega / \square$ sheet resistance. For such a low sheet resistance, presented method has the lowest thermal curing time among all single layer Ag NP printing studies in the literature. An experimental model is presented for the sheet resistance - aspect ratio relation for both methods. Time dependent resistance shifts of the lamination cured sensors are also inspected and proved to be insignificant. We state lamination curing as an advantageous and reliable alternative to oven curing and other fast curing methods both for sensor and circuitry printing implementations.
\end{abstract}

Index Terms-Angle Sensors, Flexible Sensors, Foldable Robotics, Printed Sensors

\section{INTRODUCTION}

$\mathbf{I}$ Ntegrated angle proprioception in flexible hinges is a desired function as a part of the ultimate goal of the soft robotics field [1]-[11]. This projection promotes the least number fabrication steps, methods and the lowest cost possible [1].

Inkjet printing is the most preferred method for the flexible electronics, especially in R\&D applications [12]. Ando and Baglio [13] introduces and highlights the advantages of allsingle-material printed strain sensors, using silver nanoparticle (Ag NP) ink and low-cost office type inkjet printers. Silver ink, despite being widely used in flexible electronics [5], [13]-[16], has not been implemented as a hinge angle sensor material. Existing printed angle sensors for the flexible hinges use multiple materials, a functional ink (i.e. carbon [7], [9], Pedot:PSS [6]) for the sensing pattern and a highly conductive ink (i.e. Ag NP) for the electrodes.

In this study, we consider Ag NP ink as an angle sensor material, and investigate an alternative curing method (i.e. lamination curing), to the commonly used time consuming or high cost curing methods.

$\mathrm{Ag}$ NP inks require post-printing curing processes to become electrically conductive, as the ink solutions contain non-conductive compounds (stabilizers) to facilitate printing, which avoid conductive particles to contact each other [17]. A common method is detaching these insulating solvents with thermal processes.

Authors were with Istanbul Technical University, Mechanical Engineering Department, Flexible Systems Laboratory (turkmend@itu.edu.tr, acerm@itu.edu.tr). Authors would like to thank Shahrad Samankan for his valuable advices during the preliminary studies.
Ando and Baglio, in their leading study on all-low-costinkjet-printed strain sensors [13], use oven curing (60 min, $90^{\circ} \mathrm{C}$ ) for the NovaCentrix Melaton JS-B15P Ag NP ink prints on a PET substrate with a low-cost Epson inkjet printer. Reported resistance values of strain gauge patterns correspond approximately to $0.2-0.3 \Omega / \square$ sheet resistance $\left(\sim 2.10^{6} \mathrm{~S} / \mathrm{m}\right.$ conductivity for the reported $1.9 \mu \mathrm{m}$ print thickness).

Hot plate curing is another thermal curing method used for inkjet Ag NP inks printed on flexible substrates [18], [19]. A characterization study [19] using a high-cost inkjet printer (Dimatix 2831), showed 4 layers of printing and 30 minutes hot plate curing at $120^{\circ} \mathrm{C}$ is needed for a $18 \times 10^{6} \mathrm{~S} / \mathrm{m}$ conductivity of silver prints on PET substrate (x4.4 resistivity of bulk Ag, for the reported $4.48 \mu \mathrm{m}$ print thickness $\sim 0.012$ $\Omega / \square$ sheet resistance).

Wünscher et al. reviews the alternative curing approaches for the inkjet printed metal inks on flexible substrates [17]. Microwave sintering is a newly developed method which increase the conductivity of the Ag NP inks just in seconds. However this method yet does not provide a homogeneous performance along the specimens [17]. Photonic sintering is one other fast method which applies selective heating to the printed patterns and enables higher curing temperature without damaging the substrate. However this technology still requires a high cost of price and/or technical effort [17], [20]. Plasma sintering, which uses a relatively available equipment for lab scale research studies, requires at least 30 minutes of sintering time for NP based inks [17]. Chemical sintering approaches also exist, which target decomposition of the solvents without heating, by sintering agent addition to the inks, substrate coatings or as a post treatment [17], [21].

Beisteiner reports using the commercial instant self curing 
ink NBSIJ-MU01 by Mitsubishi Paper Mills (MPM) [21] with an Epson Stylus Photo 1500W printer and Epson photo paper substrate. $15.10^{6} \mathrm{~S} / \mathrm{m}$ conductivity ( $\mathrm{x} 4$ resistivity of bulk $\mathrm{Ag}, \sim 0.08 \Omega / \square$ square resistance for the reported $800 \mathrm{~nm}$ print thickness) is achieved after printing, without any further thermal process. However, for many cases a photo paper is not sufficient to provide the mechanical properties required for an angle sensor. Same process with Mitsubishi NB series PET film gives the half conductivity $(\sim 0.2 \Omega / \square)$ [22]. Kawahara $e t$ al. reports a similar sheet resistance with the same Mitsubishi ink-substrate combination, $0.21 \Omega / \square$, using a Brother DCPJ140w printer [15]. Finally Asri reports a sheet resistance of $\sim 0.1 \Omega / \square$ based on a 11.3 aspect ratio pattern, for $1.5 \mu \mathrm{m}$ print thickness with Epson L310 inkjet printer [16]. However the samples were printed in double layers and cured for 30 minutes at $60-150{ }^{\circ} \mathrm{C}$ in this study. All studies use number of squares method to obtain sheet resistances from specimens at different aspect ratios, rather than a four probe method. This makes the results not fully comparable as the calculated sheet resistances are reported to be dependent on the pattern aspect ratio [15], [22].

Hidayanti designs and uses a lamination machine to decrease the resistances of screen printed silver ink patterns on HVS paper and Mica film [23]. $0.11 \mathrm{ohm}$ resistance is reported for a specimen with a 25 aspect ratio, after 20 seconds of lamination curing at $70{ }^{\circ} \mathrm{C}$. However data presented in this study has a very poor consistency (reported resistances increase with decreasing aspect ratio of the pattern, which is controversial to the electrical resistance theory). Beisteiner laminates the inkjet printed silver nanoparticle strain sensors with a protective elastomer layer, but the lamination effect on the electrical properties of the sensors are not studied [24].

We use a low-cost lamination machine, Olympia A3048, to cure the printed patterns with NovaCentrix Melaton JS-B25P $\mathrm{Ag}$ NP ink on the Novelle PET substrate using a low-cost office-type inkjet printer, Epson L351. We refer "lamination curing" as a thermal sintering method, using the heat and mechanical pressure of the lamination machine rollers, without using any cover foils. We also implement the conventional oven curing at various temperatures and times to compare the lamination curing performance. Sheet resistances are obtained with van der Pauw method. Parameters contributing to the sensor uncertainty (such as pattern placement on the substrate, sample size and placement into the oven) are investigated for both methods using a p-value correlation significance test. Experimental models are built for the aspect ratio $\left(r_{a}\right)$ and lamination parameters (number of pass, protective paper thickness, and heat level) effects on the resistance. Finally, angle sensors are printed and cured with both methods. Samples are tested in both compression and tension directions, in terms of cyclic and static drift, \% resistance change, nonlinearity, hysteresis and acceleration dependency. Lamination curing is found to give a $\% 33$ lower sheet resistance $(0.06 \Omega / \square$, same with provided by the ink manufacturer) than oven curing, with a lower uncertainty and taking $\% 80$ shorter time (3 minutes). Overall angle sensing performance of the lamination cured samples are also found to be higher and more consistent compared to oven cured sensors. We believe lamination curing for Ag NP printed angle sensors would accelerate the research studies by providing a fast, low-cost and reliable fabrication method.

Used oven and lamination curing techniques are explained in Section II, together with the measurement methods and experimental procedure. Section III compares the curing method performances through the findings on the curing method related fabrication uncertainty, curing parameter relations with the resulting sample resistances, sheet resistances of the samples and angle sensing performances. Final section underlines the main advantages found for the lamination curing and states the significance of the method against other alternatives.

\section{Methods}

\section{A. Inkjet printing}

Samples are printed using an Epson L350 office type desktop inkjet printer. Ag NP ink (NovaCentrix JS-B25p) is filled to all the printer cartridges. Printing parameters are set as; colored, highest quality, Epson premium glossy photo-paper. High speed print option is unchecked (note that later experiments with checked high speed option showed no significant difference in the sheet resistances and sensing behaviours of the printed samples).

Two sets of patterns are used for the experiments. Pattern set I (Fig. 1-c) consists of 9 equally distributed $1 \times 1 \mathrm{~cm}$ squares to inspect the pattern \& sample placement, reproducibility and lamination direction effects. Pattern set II (Fig. 1-e) consists of 9 rectangles with varying aspect ratios (1 to 50) and it is used to compare the geometry and time dependencies of the pattern resistances cured with two distinct methods. Finally an angle sensor pattern (Fig. 1-f) is printed to inspect the variations on the angle sensing behaviours of the samples among two curing methods.

\section{B. Curing}

Based on the information provided by NovaCentrix support service, the chemical composition of Novelle PET substrate coating facilitates the decomposition of the stabilizers in NovaCentrix ink, and allows the patterns to become conductive in lower temperatures. Oven curing and lamination curing methods are implemented to the samples printed under the same conditions.

1) Oven curing: Memmert UN 55 oven is employed for the oven curing experiments. $100^{\circ} \mathrm{C}$ and $120^{\circ} \mathrm{C}$ curing temperatures are tested for 15,25 and 60 minutes curing times to investigate the curing capabilities. Samples are placed to the oven after the curing temperatures are reached and oven timer is also set to start after the curing temperature is reached. Oven air flap is set $50 \%$ open for all experiments.

2) Lamination curing: A low-cost $(<150 \$)$ desktop laminator, Olympia A 3048, is used to cure the printed samples. Device uses four heating rollers to laminate foils in a range of 80 to $250 \mu \mathrm{m}$ of thickness. However here we use the lamination machine without any foils, only to heat the printed samples. PET layer is enveloped between two paper layers to avoid direct contact with the rollers (Fig. 1-b). Three heating levels of the device $(80 \mu \mathrm{m}, 125 \mu \mathrm{m}, 250 \mu \mathrm{m})$ are used with 

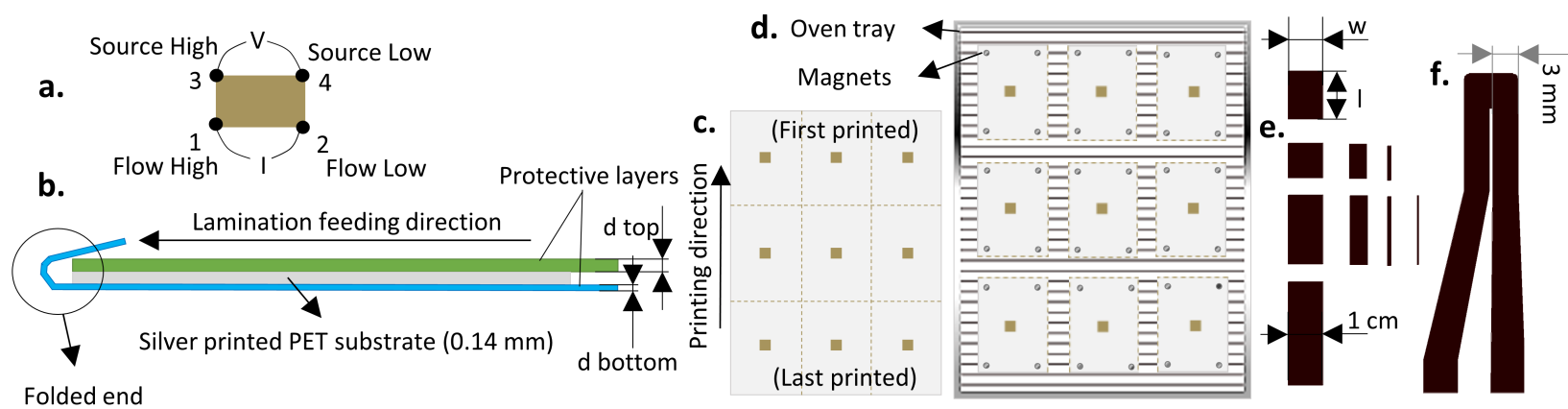

Fig. 1. a. Measurement configuration used with the four terminal LCR-meter for a sample with an arbitary aspect ratio. A square sample is used for the van der Pauw method measurement. b. Schematic respresentation of the laminating configuration of the sensor printed substrate and sandwiching protective layers. The edge of the thinner layer is folded at the feeding side, to avoid any slip between the layers. c. Schematic representation of a printed sample (pattern set I). d. Schematic representation of sample placement on the oven tray for curing. PET substrate is cut into equal pieces and fixed on the tray with magnets at the corners. e. Pattern set II. f. Angle sensor pattern. experiments.

different paper thicknesses and numbers of lamination cycles (number of pass) to optimize the curing process. Device has a $600 \mathrm{~mm} / \mathrm{min}$ laminating speed and a warm up time about 3-5 minutes.

\section{Sheet resistance measurements}

Sheet resistance (i.e. surface resistivity, square resistance) is obtained with two approaches in the literature. One is to use four probe or van der Pauw methods [25] and other is to divide the overall resistance of a pattern to the aspect ratio (number of squares) along the conductive path [26]. Sheet resistances obtained with these two methods may give slightly different values depending on the minimum width and aspect ratio of the used patterns in the latter method [15], [22].

We use van der Pauw technique to obtain the sheet resistance of the printed patterns as it is a more feasible method for small sized patterns compared to the four probe method [27]. Sheet resistances of the square patterns are found with 1 , where $I_{12}$ is the current flow given to the specimen through points 1 and 2, and $V_{34}$ is the measured voltage drop between points 3 and 4 (Fig. 1-a) [27]. A GW Instek 6020 LCR-meter is used for the measurements.

$$
R_{\text {sheet }}=4.532 \cdot \frac{V_{34}}{I_{12}}
$$

\section{Sensor behaviour testing}

A 3D printed setup is used to test the angle sensor behaviours (Fig. 2). Sensors are bent from $0^{\circ}$ (flat position) to $90^{\circ}$ both in compression and tension directions. Approximate radius of curvature of the sensors at $90^{\circ}$ is $1 \mathrm{~mm}$.

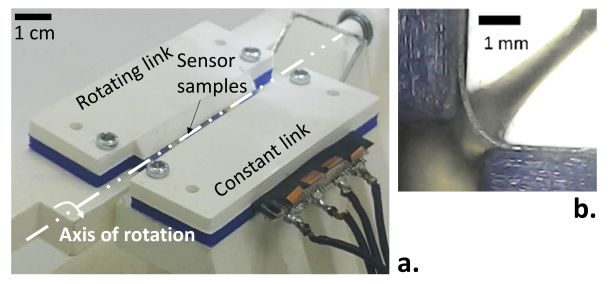

Fig. 2. a. Experimental setup used for angle sensor implementation. b. Side view of the sensor at $90^{\circ}$ joint angle.
Sensor responses are measured with a simple voltage divider circuit and a data acquisition card (ni USB DAQ) at 20 $\mathrm{Hz}$. Rotational joint is actuated with a DC-motor (Dynamixel XL430-W250-T). A triangular wave between $0-90^{\circ}$ at 10 sec period and a stepwise trajectory of $10^{\circ}$ steps with 5 seconds stops from 0 to 90 and back to $0^{\circ}$ are used for the tests (graphically represented in the results section). Mean resistance data is obtained from last 1 second of each step. Performance tests for each sample are conducted after 30 cycles of triangular wave.

\section{Results}

\section{A. Fabrication uncertainty}

It is important to fabricate maximum number of samples at a single batch with a minimum variance in the sample resistances, for consistency in research studies or any other application purposes. In order to compare the uncertainties introduced by the curing methods, pattern set I is printed and cured with varying curing parameters.

Among the 4 levels of slides in the oven chamber, level 2 and 3 (numerated from bottom to top) are tested with cut (Fig. 1-d) and uncut letter-sized (whole) samples (Fig. 1-c). For the lamination curing investigation, uncut samples are fed into the lamination machine both in the opposite direction to the printing direction (feed direction 1) and in the direction of the printing direction (feed direction 2) (Fig. 1-b, c).

Recalling pattern set 1 has 3 rows and 3 columns, Fig. 3 shows the row and column dependency of the sheet resistances for oven and lamination curing. Oven cured sample data all together has a population number of 171, and found to show a statistically significant correlation with the row number (i.e. printing order) (p-value $<0.05)$. Results indicate that the first printed patterns tend to have lower sheet resistances than the latter. No dependency is observed to the column number.

Lamination cured samples are analyzed in two populations, population $1(n=36)$ where the samples are fed into the machine in direction 1 and population $2(n=45)$ where the samples were fed in direction 2. 24 members of population 2 were cured after cut into single columns and not included in the column dependency analysis. Results showed that although lamination in direction 1 has an even higher dependency to 


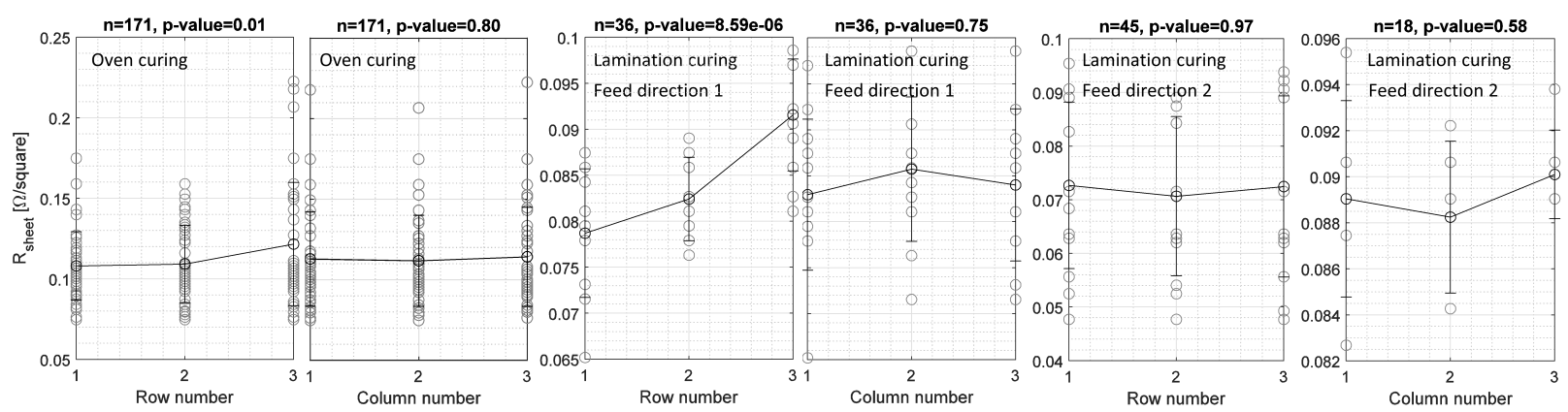

Fig. 3. Sheet resistance distributions w/to column and row numbers of the square patterns in pattern set I. Lamination curing in feed direction 2 shows the lowest dependency to the row number.

the row number, no significant correlation exist when the feeding direction 2 is applied. No correlation is found with the column number, similar with the oven curing. Results show that lamination curing in direction 2 is more advantageous than oven curing in terms of pattern placement independency.

A second analysis is done with the same data sets to compare the amounts of resistance deviation within a column. (Row deviation is neglected.) To measure the uncertainty, the mean relative standard deviation value is calculated as,

$$
\text { mean relative } \mathrm{SD}=\frac{\sum_{i}^{N} \frac{\sigma_{c, i}^{2}}{\overline{c_{i}}}}{N}
$$

where $\mathrm{N}$ is the number of columns and $\sigma_{c}$ and $\bar{c}$ are the standard deviation and mean of the sheet resistance values within a column. Results are listed in Table I. A combined configuration for the oven curing (cut \& level 2) showed the lowest deviation (2\%). Lamination curing in feed direction 2 yielded a $3 \%$ uncertainty. Overall resistance variations within the columns are $37 \%$ lower with lamination curing.

TABLE I

UNCERTAINTIES OF OVEN AND LAMINATION CURING METHODS, IN TERMS OF MEAN RELATIVE STANDARD DEVIATION. N IS THE NUMBER OF SAMPLE COLUMNS.

\begin{tabular}{cccc|cc}
\multicolumn{4}{c|}{ Oven } & \multicolumn{2}{c}{ Lamination } \\
\hline $\begin{array}{c}\text { Cut } \\
(\mathrm{N}=21)\end{array}$ & $\begin{array}{c}\text { Whole } \\
(\mathrm{N}=24)\end{array}$ & $\begin{array}{c}\text { Level 2 } \\
(\mathrm{N}=21)\end{array}$ & $\begin{array}{c}\text { Level 3 } \\
(\mathrm{N}=24)\end{array}$ & $\begin{array}{c}\text { Feed dir. 1 } \\
(\mathrm{N}=12)\end{array}$ & $\begin{array}{c}\text { Feed dir. 2 } \\
(\mathrm{N}=15)\end{array}$ \\
\hline $5 \%$ & $11 \%$ & $5 \%$ & $12 \%$ & $9 \%$ & $3 \%$ \\
\hline Cut + Level 2: & $2 \%(\mathrm{~N}=9)$ & & & \\
\hline \multicolumn{3}{r|}{ Overall: $8 \%(\mathrm{~N}=57)$} & & Overall: 5 \% $(\mathrm{N}=27)$
\end{tabular}

\section{B. Curing parameters}

1) Oven: The minimum attainable sheet resistance for the printed samples are found to be $0.12 \Omega / \square$ with the oven curing (Fig. 4-a). While 15 minutes curing at $120^{\circ} \mathrm{C}$ is suffice for achieving this value, a safer temperature for the PET material, $100^{\circ} \mathrm{C}$, needs an hour of curing time.

Visually inspected samples of cut PET sheet showed noticeable shape distortions (folding) at both curing temperatures, despite the magnets placed to fix the samples onto the oven grid (Fig. 1-d). Lamination cured substrates did not show significant shape change. Transferring the sheet to a flatly secured place (e.g. a storage file ) following the lamination,
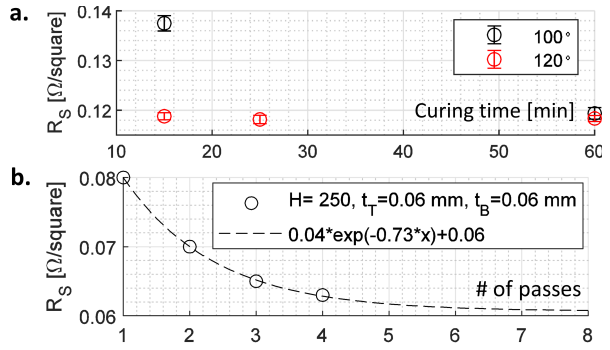

Fig. 4. a. Sheet resistance dependency on the oven curing temperature and curing time. b. Sheet resistance dependency on the lamination pass number is represented with an exponential function.

completely eliminates the bending. Undesired bending of the samples may cause an-isotropic mechanical behavior of the sensors when folded into compression and tension sides.

2) Lamination: Experiment results showed that the sheet resistance of the samples tend to decrease exponentially with increasing heat level, number of passes and decreasing cover layer thickness. Approximated models for this dependency are presented in Fig. 4 and 5. The lowest sheet resistance samples settled at is achieved with the configuration $250 \mu \mathrm{m}$ heat level, $60 \mu \mathrm{m}$ top and bottom cover layers and 4 lamination passes (Table II). This sheet resistance value is in the range provided by the ink manufacturer $(0.06-0.07 \Omega / \square)$, obtained with photonic curing of the samples printed on the same substrate as used in this study.

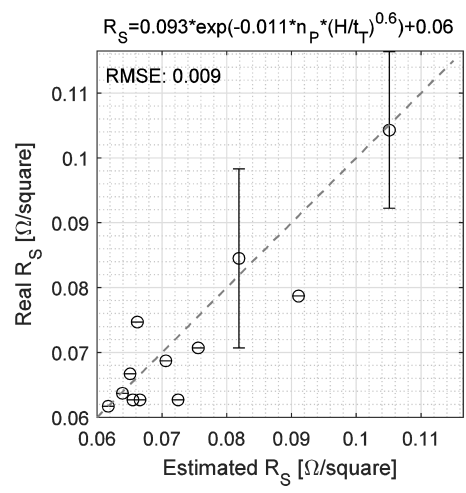

Fig. 5. Goodness-of-fit representation of the sheet resistance model as a function of lamination heat level $(\mathrm{H})$, number of pass $\left(\boldsymbol{n}_{\boldsymbol{p}}\right)$ and total cover layer thickness $\left(t_{T}=t_{T o p}+t_{B o t t o m}\right)$.

One drawback of this combination is the crease formed 
TABLE II

SHEET RESISTANCES WITH VARYING LAMINATION PARAMETERS. T AND B STANDS FOR TOP AND BOTTOM PAPER LAYER THICKNESS IN $\mu \mathrm{M}$. C STANDS FOR PAPER CREASE AND Y\&N FOR YES\&NO.

\begin{tabular}{|c|c|c|c|c|c|c|c|c|}
\hline & & & \multicolumn{5}{|c|}{ Number of passes \& $R_{S}[\Omega / \square]$} & \multirow[b]{2}{*}{$\mathrm{C}$} \\
\hline $\begin{array}{l}\text { Heat } \\
\text { level }\end{array}$ & $\mathrm{T}$ & B & 1 & 2 & 3 & 4 & 5 & \\
\hline 80 & 60 & 20 & - & - & - & - & 0.08 & $\mathrm{Y}$ \\
\hline 125 & 60 & 60 & 0.11 & 0.09 & - & - & - & $\mathrm{Y}$ \\
\hline \multirow{4}{*}{250} & 60 & 60 & 0.08 & 0.07 & 0.07 & 0.063 & - & $\mathrm{Y}$ \\
\hline & 120 & 120 & - & - & - & 0.064 & - & $\mathrm{Y}$ \\
\hline & 60 & 210 & - & - & 0.064 & 0.064 & - & $\mathrm{Y}$ \\
\hline & 120 & 210 & - & - & $\underline{0.072}$ & - & 0.068 & $\underline{N}$ \\
\hline
\end{tabular}

in the cover layers due to their low thickness and the high lamination temperature. While the PET substrate is not damaged, cover layer crease cause undesirable traces on the printed samples. Only combination the cover layers are not damaged and a sufficient sheet resistance is achieved is $0.12 \mathrm{~mm}$ bottom layer (common printing paper) and $0.21 \mathrm{~mm}$ top layer at 250 $\mu \mathrm{m}$ heat level. 3 lamination passes provide sufficient curing and further cycles contributions are insignificant.

As an application note, it is advised to separate and replace the cover layers after each lamination cycle to minimize distortions in the sheets due to unequal heat expansion factors of the layers.

\section{Sheet resistance}

Pattern set II resistances are printed and cured with oven and lamination curing. Lamination curing is performed at $250 \mu \mathrm{m}$ heat level, $0.12 \mathrm{~mm}$ and 0.21 top and bottom layer and 3 pass. Oven curing is performed at $120^{\circ} 15$ minutes. Sample resistances are measured with the LCR-meter with the configuration in Fig. 1-a. Using the sample resistances at $r_{a}=1$ $\left(R_{r_{a}}\right)$ and 1, the sheet resistances for the oven and lamination cured samples are found $0.09 \Omega / \square$ and $0.14 \Omega / \square$ at the fabrication day. 18th day data showed $6 \%$ and $8 \%$ decline respectively. Difference between the shift ratios found to be insignificant based on the measurement uncertainty which was calculated as $2 \%$.

It should be remarked here that the sheet resistances obtained with both methods differ from the data collected from the pattern set I, (Table II, Fig. 5). In Fig. 6-b $\left(R_{\mathrm{S} \text {, Oven }}, R_{\mathrm{S} \text {, Lamination }}\right)$ data pairs belonging to different samples fabricated at different days are plotted. A constant ratio between the sheet resistances indicates that the major shift seen in the resistance is independent of the curing processes. Possible causes of the shift may be the printing process or the varied ambient conditions such as humidity.

In order to compare specimen resistances at different aspect ratios cured with two methods, measured resistances $\left(R_{r_{a}}\right)$ are expressed in terms of sheet resistance as in 3, where $\mathrm{F}$ is defined as a coefficient dependent on $r_{a}$.

$$
R_{r_{a}}=R_{\text {sheet }} \cdot r_{a} \cdot F\left(r_{a}\right)
$$

Fig. 6-c shows the $\mathrm{F}$ curves obtained with two curing methods do intersect. Notice $\mathrm{F}(1)$ on the graph corresponds to $0.22(1 / 4.532)$ based on 3 . However F does not converge to 1 with the increasing aspect ratio, which yields a discrepancy between the sheet resistance values obtained with van der Pauw method and values that number of squares method would give. $F\left(r_{a}\right)$ is approximated with the exponential function given in Fig. 6-c.

\section{Angle Sensor behavior}

Sensor patterns (Fig. 1-f) cured with lamination and oven curing are tested in the experimental setup both in the tension and compression side folding directions. Lamination curing is performed at $250 \mu \mathrm{m}$ heat level, $0.12 \mathrm{~mm}$ and $0.21 \mathrm{~mm}$ top and bottom layers and 3 pass. Oven curing is performed at $120^{\circ} 15$ minutes. Four samples are tested for each method. Mean sensor resistances are measured as 1.6 and $2.1 \Omega / \square$ respectively. Two of the samples are tested in the fabrication day and two in the day after.

In order to measure sensor performances triangular (Fig. 6a) and step (Fig. 7) trajectories are used. Inspected parameters for the ramp cycle response are; the percentage resistance change between the flat and $90^{\circ}$ folded position w/to flat state sensor resistance $\mathrm{R}_{0}\left(\% \Delta R_{0-90}\right)$, percentage drifts of the $\mathrm{R}_{0}$ and $\mathrm{R}_{90}$ resistances at the end of a 5-cycle set (\% Drift and $\%$ Drift $_{90}$ ) (Fig. 6-a), mean hysteresis error in degrees, and nonlinearity in terms of root mean square error (RMSE) between the sensor response and the line $R_{\text {Norm }}=\theta / 90$. Normalized resistances of the sensors are calculated with,

$$
R_{\text {Norm }}=\frac{R_{\theta}-R_{0}}{R_{90}-R_{0}}
$$

Performance parameters for the step response are; percentage resistance change between the flat and $90^{\circ}$ positions, mean percentage absolute drift at the resistances during the wait time of the steps, mean signal to noise ratio (SNR), hysteresis error in degrees, and nonlinearity in RMSE (Fig. 8).

Sensors cured with two methods are found to show similar behaviours. Lamination cured sensors gave a higher resistance change ratio. They were also tend to show lower static and cyclic drifts. SNR of the lamination cured samples are observed higher and less varied. Although lamination cured samples showed higher nonlinearity, deviations in the RMSE were lower, which would provide a lower calibration uncertainty (Fig. 8).

Stepwise trajectory is aplied with two different deceleration profiles (sharp and smooth) (Fig. 8) to investigate the robustness of the sensor behaviours to dynamic effects. Lamination cured sensors showed similar behaviours for both profiles where oven cured sensor responses differed.

An overall score is calculated with the formulation in 5 based on all performance parameters $(p)$ listed in Fig. 8. Lamination cured sensors are found to give better overall performance than oven cured sensors with higher consistency.

$$
\text { Overall Score }=\frac{\sum_{i^{n_{p}}} \frac{p_{i}-p_{\text {worse }}}{p_{\text {best }}-p_{\text {worse }}}}{n_{p}}
$$




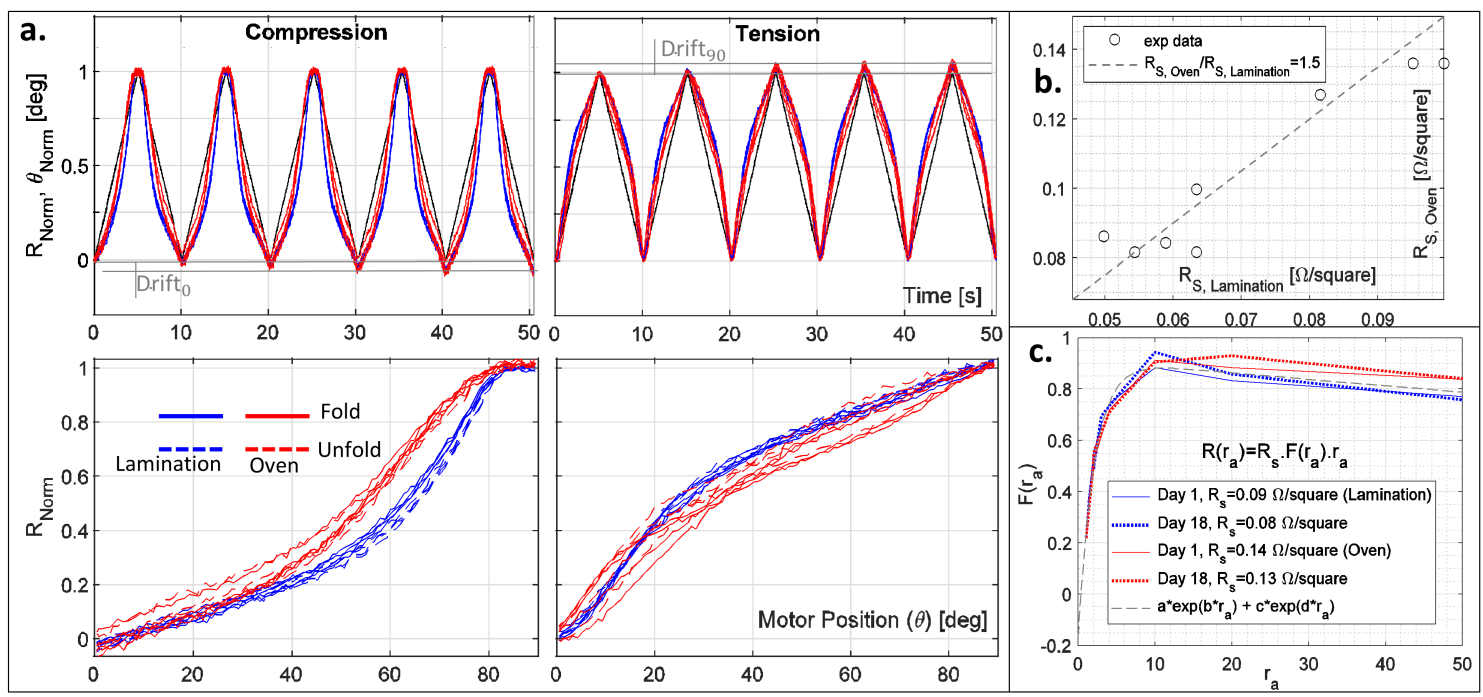

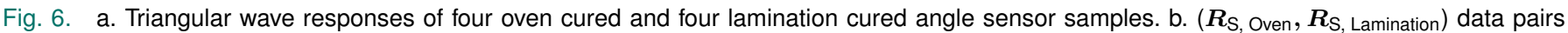
belonging to different day of fabrication. Lamination curing is performed at $250 \mathrm{mic}, 0.12 \mathrm{~mm}$ and 0.21 top and bottom layer and 3 pass. Oven curing is performed at $120^{\circ} 15$ minutes. c. Experimental model for the sheet resistance geometric factor $\boldsymbol{F}\left(\boldsymbol{r}_{\boldsymbol{a}}\right)$. Sheet resistance $\boldsymbol{R}_{\boldsymbol{s}}$, obtained with the Van der Pauw method, is the aspect ratio $\left(\boldsymbol{r}_{\boldsymbol{a}}\right)$ of the printed pattern and a geometrical factor $F$ which is found to be a function of the $\boldsymbol{r}_{\boldsymbol{a}}$. a=0.918, $b=-0.003, c=-1.083, d=-0.473$.

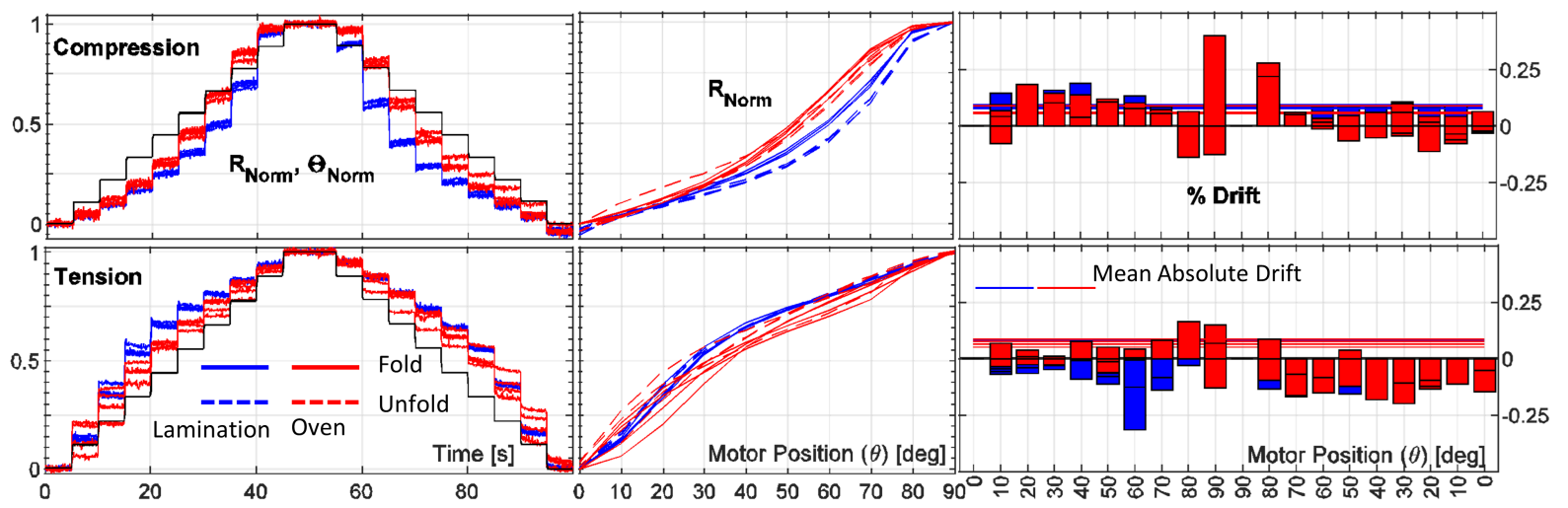

Fig. 7. Step responses of four oven cured and four lamination cured angle sensor samples. Higher deviation is observed in the oven cured samples both in time response (column 1), mean steady state response (column 2) and static drifts (column 3).
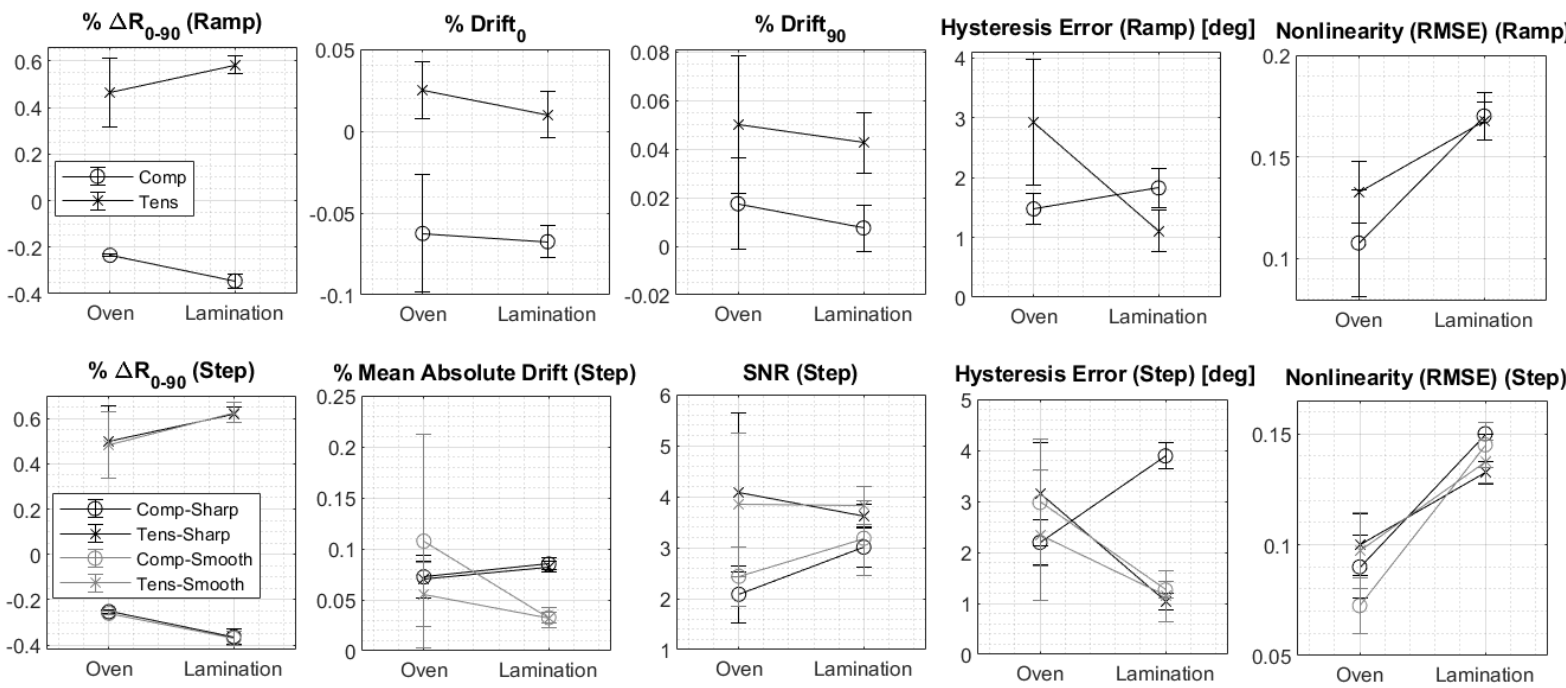

Fig. 8. Performance statistics of four oven cured and four lamination cured angle sensor samples. Lamination curing gave higher performance in all metrics except nonlinearty, and lower uncertainty in all metrics. 


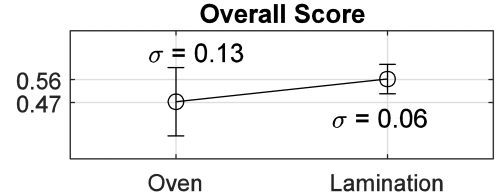

Fig. 9. Overall score of the sensors $(\mathrm{N}=4)$. Lamination cured sensors gave a higher performance with lower uncertainty.

\section{CONCLUSIONS AND Discussions}

Lamination curing method is found to be a sufficient standalone curing method for Ag NP inkjet printed patterns on coated PET substrate. It is also found advantageous compared to the conventional oven curing method mainly due to;

- $80 \%$ Faster curing time,

- 33\% Higher conductivity,

- Less fabrication uncertainty,

- Better and more consistent angle sensing performance.

With lamination curing method, sheet resistances provided by the ink manufacturer $(0.06-0.07 \Omega / \square)$ are reached in 3 minutes, using the same coated substrate with the company. Although the curing system used by the manufacturer has the capability of an instant curing ( $<<1$ millisecond), lamination machine has a far achievable cost $(150 \$$ vs. $55.000 \$)$.

Minimum sheet resistance achieved with oven curing was $33 \%$ higher than the lamination curing provided, and required 15 min curing. Note that lamination machine has also a short warm-up time (5 min), where the oven used in study (1900\$) required around 15 minutes to reach the curing temperature $\left(120^{\circ} \mathrm{C}\right)$.

One low-cost curing method providing a shorter curing time (instant) is chemical curing (i.e. Mitsubishi self curing inkjet ink [21]). However studies using this ink report more than 2 times of the sheet resistances achieved with lamination curing [15], [24]. Still, for the cases where lower conductivity is tolerable, self curing ink can also be an alternative to lamination curing.

Oven cured sample resistances showed a significant dependency to the printing order, where lamination curing in the printing direction eliminated this dependency. We note that this ability may also allow lamination curing to be employed in a roll-to-roll (R2R) manufacture process. Overall uncertainty of the lamination process is found to be lower than oven curing. Oven curing, only when the samples are cut and placed on the $2^{\text {nd }}$ slide gave a slightly lower uncertainty than lamination curing. This limits number of maximum samples cured in a batch to a single sheet. Small sized sample oven curing also caused major thermal distortions on the samples, despite the magnets used to secure on the grid.

Finally, lamination cured angle sensors are found to give better performances in all metrics, except nonlinearity. However both the nonlinearity and overall score of the lamination cured sensors showed half the deviation observed in the oven cured sensors.

\section{ACKNOWLEDGMENT}

This work was supported by the Scientific and Technological Research Council of Turkey (TUBITAK) (Grant No.
216M193).

\section{REFERENCES}

[1] "The soft touch of robots," Nature Reviews Materials, vol. 3, p. 71, 2018.

[2] T. L. Mohren, T. L. Daniel, S. L. Brunton, and B. W. Brunton, "Neural-inspired sensors enable sparse, efficient classification of spatiotemporal data," Proceedings of the National Academy of Sciences, vol. 115 , no. 42 , pp. 10564-10569, 2018. [Online]. Available: https://www.pnas.org/content/115/42/10564

[3] H.-S. Shin, L. Castano, J. Humbert, and S. Bergbreiter, "Sensing skin for detecting wing deformation with embedded soft strain sensors," 2016 IEEE SENSORS, pp. 1-3, 2016.

[4] J. Tapia, E. Knoop, M. Mutný, M. A. Otaduy, and M. Bächer, "Makesense: Automated sensor design for proprioceptive soft robots," Soft Robotics, vol. 7, no. 3, pp. 332-345, 2020, pMID: 31891526. [Online]. Available: https://doi.org/10.1089/soro.2018.0162

[5] S. Zhang, L. Cai, W. Li, J. Miao, T. Wang, J. Yeom, N. Sepúlveda, and C. Wang, "Fully printed silver-nanoparticle-based strain gauges with record high sensitivity," Advanced Electronic Materials, vol. 3, no. 7, p. 1700067,2017

[6] B. Kwak and J. Bae, "Compliant mechanosensory composite (cmc): a compliant mechanism with an embedded sensing ability based on electric contact resistance," Smart Materials and Structures, vol. 27, no. 12 , p. $125003,2018$.

[7] X. Sun, S. M. Felton, R. J. Wood, and S. Kim, "Printing angle sensors for foldable robots," 2015 IEEE/RSJ International Conference on Intelligent Robots and Systems (IROS), 2015.

[8] M. E. Nisser, S. M. Felton, M. T. Tolley, M. Rubenstein, and R. J. Wood, "Feedback-controlled self-folding of autonomous robot collectives," in 2016 IEEE/RSJ International Conference on Intelligent Robots and Systems (IROS). IEEE, 2016, pp. 1254-1261.

[9] A. Firouzeh, A. F. Amon-Junior, and J. Paik, "Soft piezoresistive sensor model and characterization with varying design parameters," Sensors and Actuators A: Physical, vol. 233, pp. 158-168, 2015.

[10] M. Luo, E. H. Skorina, W. Tao, F. Chen, S. Ozel, Y. Sun, and C. D. Onal, "Toward modular soft robotics: Proprioceptive curvature sensing and sliding-mode control of soft bidirectional bending modules," Soft robotics, vol. 4, no. 2, pp. 117-125, 2017.

[11] "A-puffer, a foldable robot that can access tight spaces," https://www.jpl.nasa.gov/robotics-at-jpl/a-puffer, accessed: 2021-07-06.

[12] J. Wiklund, A. Karakoç, T. Palko, H. Yiğitler, K. Ruttik, R. Jäntti, and J. Paltakari, "A review on printed electronics: Fabrication methods, inks, substrates, applications and environmental impacts," Journal of Manufacturing and Materials Processing, vol. 5, no. 3, p. 89, 2021.

[13] B. Ando and S. Baglio, "All-inkjet printed strain sensors," IEEE Sensors Journal, vol. 13, no. 12, pp. 4874-4879, 2013.

[14] S. Kim, S. Won, G.-D. Sim, I. Park, and S.-B. Lee, "Tensile characteristics of metal nanoparticle films on flexible polymer substrates for printed electronics applications," Nanotechnology, vol. 24, no. 8, p. 085701, 2013.

[15] Y. Kawahara, S. Hodges, B. S. Cook, C. Zhang, and G. D. Abowd, "Instant inkjet circuits: lab-based inkjet printing to support rapid prototyping of ubicomp devices," in Proceedings of the 2013 ACM international joint conference on Pervasive and ubiquitous computing, 2013, pp. $363-372$.

[16] M. A. M. Asri, N. A. Ramli, and A. N. Nordin, "Electrical performance and reliability assessment of silver inkjet printed circuits on flexible substrates," Journal of Materials Science: Materials in Electronics, pp. 1-14, 2021.

[17] S. Wünscher, R. Abbel, J. Perelaer, and U. S. Schubert, "Progress of alternative sintering approaches of inkjet-printed metal inks and their application for manufacturing of flexible electronic devices," Journal of Materials Chemistry C, vol. 2, no. 48, pp. 10232-10261, 2014.

[18] E. Sowade, H. Kang, K. Y. Mitra, O. J. Weiß, J. Weber, and R. R. Baumann, "Roll-to-roll infrared (ir) drying and sintering of an inkjetprinted silver nanoparticle ink within 1 second," Journal of Materials Chemistry C, vol. 3, no. 45, pp. 11 815-11 826, 2015.

[19] M. A. Riheen, T. K. Saha, and P. K. Sekhar, "Inkjet printing on pet substrate," Journal of the Electrochemical Society, vol. 166, no. 9, p. B3036, 2019.

[20] "Novacentrix pulse-forge photonic curing system," https://store.novacentrix.com/category-s/1832.htm, accessed: 2021$09-11$. 
[21] "Mitsubishi paper mills self curing silver ink," https://www.mpm.co.jp/electronic/eng/silver-nano/faq.html, accessed: 2021-09-11.

[22] C. Beisteiner, R. Gstöttenmayr, T. Altmanninger, and B. G. Zagar, "Charakterisierung von mechanischen und elektrischen eigenschaften funktionaler inkjet-gedruckter strukturen:", tm - Technisches Messen, vol. 83, no. 11, pp. 647-659, 2016. [Online]. Available: https://doi.org/10.1515/teme-2016-0017

[23] F. Hidayanti, K. Lestari, and R. Anwar, "Arduino based conductive silver lamination device," International Journal of Emerging Trends in Engineering Research, vol. 8, no. 2, pp. 265-270, 2020.

[24] C. Beisteiner and B. G. Zagar, "A survey of inkjet-printed low-cost sensors," tm-Technisches Messen, vol. 85, no. 7-8, pp. 504-514, 2018.

[25] I. Miccoli, F. Edler, H. Pfnür, and C. Tegenkamp, "The 100th anniversary of the four-point probe technique: the role of probe geometries in isotropic and anisotropic systems," Journal of Physics: Condensed Matter, vol. 27, no. 22, p. 223201, 2015.

[26] J. Suikkola, T. Björninen, M. Mosallaei, T. Kankkunen, P. Iso-Ketola, L. Ukkonen, J. Vanhala, and M. Mäntysalo, "Screen-printing fabrication and characterization of stretchable electronics," Scientific reports, vol. 6 , no. 1, pp. 1-8, 2016.

[27] J. Pütz, S. Heusing, and M. Aegerter, "Characterization of electrical properties," Handbook of Sol-Gel Science and Technology; Klein, L., Aparicio, M., Jitianu, A., Eds, pp. 1-30, 2005.

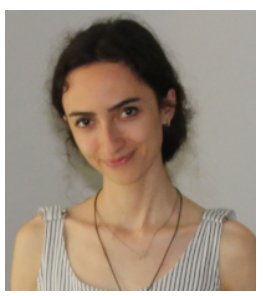

Dila Türkmen is a Ph.D. student and Research Assistant in Istanbul Technical University (ITU), Mechanical Engineering Department, where she completed her B.S. and and M.S. degrees in 2013 and 2016.

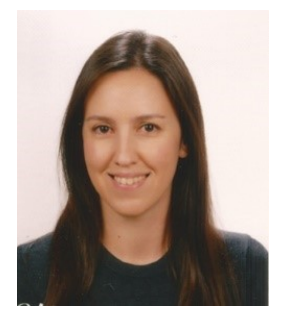

Dr. Merve Acer Kalafat received her B.S. degree in Mechanical Engineering from Istanbul Technical University, Turkey, in 2005. She completed her M.S and Ph.D. in Mechatronics Engineering from Sabanci University, Turkey, in 2007 and 2012, respectively. From 2005 to 2012, she has worked as a Research Assistant at Sabanci University, Microsystems Laboratory. She has been an instructor in the Mechanical Engineering department at Istanbul Technical University since 2012. During 2013-2014 she has worked as a postdoctoral researcher in École Polytechnique Fédérale de Lausanne (EPFL) at Reconfigurable Robotics Laboratory (RRL). She established Flexible Systems Laboratory under Mechanical Engineering Department in 2018 at Istanbul Technical University. Her fields of interest are soft robotics, soft sensors, compliant mechanisms, origami-based structures, mechatronics, and motion control. 